\title{
Ossification of the Ligamentum Flavum
}

\author{
Dong Ki Ahn, Song Lee, Sang Ho Moon, Kyung Hwan Boo, Byung Kwon Chang, Jae Il Lee \\ Department of Orthopedic Surgery, Seoul Sacred Heart General Hospital, Seoul, Korea
}

\begin{abstract}
Ossification of the ligamentum flavum is a rare cause of thoracic myelopathy. It develops in East Asians more frequently than in people from other areas. The exact pathophysiology has not been elucidated yet; however, it largely depends on biomechanical alterations, especially changes in the tensile force. Because the spinal cord is compressed from the posterior side, the first and most common clinical manifestation is usually loss of functional gait and spastic paralysis, which develop as the spinal cord compression progresses. The choice of diagnostic imaging is T2 sagittal magnetic resonance imaging scanning. Whole spine scanning is mandatory to identify multiple areas of compression and any associated distal lumbar diseases. Fine computed tomography imaging is necessary to make a differential diagnosis and set up a precise surgical plan. Conservative treatment does not work in this disorder. Decompression surgery is the only option and prognosis after surgical treatment is better with this disorder than with other causes of thoracic myelopathy. The severity of preoperative symptoms and the time interval before surgical treatment are the most important prognostic factors.
\end{abstract}

Key words: Ossification of ligamentum flavum; Treatment; Prognostic factors

\section{Introduction}

Ossification of the ligamentum flavum (OLF) was discovered by Polgar through a lateral X-ray film. However, the investigation of the disease began in earnest after the development of the computed tomography (CT) and magnetic resonance imaging (MRI). Amid the thoracic myelopathies, its incidence is less than that of ossification of the posterior longitudinal ligament (OPLL) and higher than that of herniated nucleus pulposus (HNP) [1]. The ligamentum flavum (LF) connects adjoining two laminas at the posterior side of the dura mater and both side flaps are separated at the midline. It extends laterally to the anterior side of the facet joint and is separated from the dura mater by epidural fat. For convenience of the explanation of the pathologic progression, LF is divided into two parts: as a capsular portion and an inter-laminar portion. In the past, OLF was considered to be a disease of mostly the Japanese, and the incidence is $20 \%$ among elderly Japanese (over 65 years of age) regardless of the symptoms [2]. However, this disease has been reported in other East Asian countries like Korea and China [3,4] and even outside of Asia [5-7].

\section{Pathophysiology and Classification}

There are two putative theories for the development of OLF: intrinsic causes such as genetic and dietary factors [8], and extrinsic causes which weighs biomechanical alterations $[9,10]$. In the past, intrinsic factors were regarded as being more important because the disorder was considered to develop only in limited areas of the world.

Received Aug 20, 2013; Revised Sep 5, 2013; Accepted Sep 5, 2013

Corresponding author: Dong Ki Ahn

Department of Orthopedic Surgery, Seoul Sacred Heart General Hospital,

259, Wangsan-ro, Dongdaemun-gu, Seoul 130-867, Korea

Tel: +82-2-968-1616, Fax: +82-2-968-2394, E-mail: adkajs@hanmail.net 
But extrinsic factors are presumed to be more important nowadays after its occurrence has been seen throughout the world [11-13]. A biomechanical mechanism as a cause of this disorder would be different in nature from the usual degenerative processes that occur due to hypermobility because the movement of the thoracic spine is limited compared to the cervical and lumbar spines. The putative mechanism is as follows. When the tensile force increases, BMP-2, TGF-beta, and SOX are elevated in the ligamentum flavum. Then, the fibroblasts become differentiated into chondroblasts and osteoblasts, and finally ossification of the ligament develops [14]. One of the reasons why it develops more frequently in East Asia is considered to be due to the more frequent squatting position adopted by members of those populations $[15,16]$. Therewith diffuse idiopathic skeletal hyperostosis, Paget's disease, fluorosis, adenocarcinomatous metastasis, hypophosphatemic vitamin D resistant rickets, hydroxiapetite and disorders of calcium metabolism may result in OLF $[17,18]$. However, the exact pathophysiology has not been fully elucidated yet. It progresses by endochondral ossification [13].

The predilection sites are the lower thoracic and high thoracic and mid thoracic areas, in order of frequency [19]. The most frequent site is between T10 and T11, and it is presumed that this is because these segments receive the maximum tensile force $[13,20]$.

Ossification begins from the capsular portion and progresses to the interlaminar portion of the LF. In the transverse plane, ossification begins from the posterior side and progresses to the dural side $[12,21]$. On both sides, the paramedian cords meet at the midline and form a nodular mass and this usually progresses in a cranial direction [6,22]. Sato classified this disorder according to the progression (Fig. 1) [23]. Lateral type means ossification of only the capsular portion. Extended type means there is extension of the ossification to the interlaminar portion but the affected part is still thin. Enlarged type means thickening of the ossification with anteromedial enlargement. Fused type means fusion of the bilateral ossified mass at the midline. Tuberous type means nodular growth of the ossified mass anteriorly. The more advanced the ossification, the more stenotic the spinal canal is.

The spinal cord eventually develops infarction and avascular necrosis due to the chronic compression. Chromatolysis occurs in the gray matter and demyelinization occurs in the white matter.

\section{Clinical Manifestations and Diagnosis}

The diagnosis is commonly missed and delayed because of its insidious and chronic progression and the frequent presence of other spinal diseases. Clinical manifestations and imaging tests are the two mainstays in the diagnosis. Local thoracic pain and stiffness and slowly progressive myelopathy are the distinctive features. In the early stage, posterior cord syndrome, i.e., loss of vibration and proprioception, develops because compression of the spinal cord usually begins from the posterior side. As the ossification progresses, the lateral corticospinal tracts are compressed and then spastic paraparesis develops. And as the area of ossification enlarges, compression of the lateral spinothalamic tracts causes loss of sensation (Fig. 2). The most common clinical manifestation at the time of the diagnosis is loss of functional gait. Radicular pain and loss
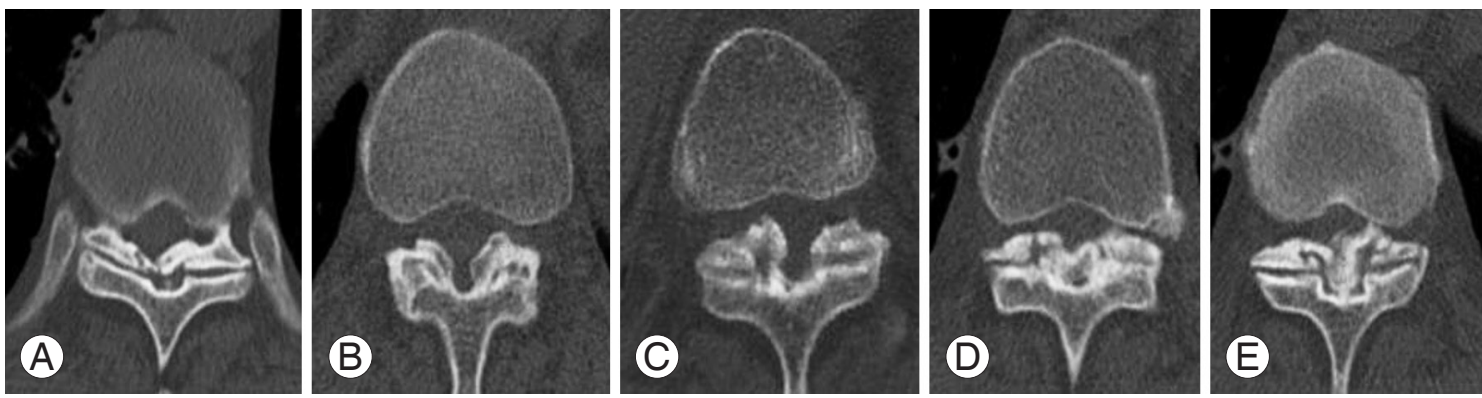

Fig. 1. Sato classification according to the progression of the ligament ossification. (A) Lateral type which means ossification of only the capsular portion of the ligamentum flavum. (B) Extended type which means extended ossification of the interlaminar portion. (C) Enlarged type which means anteromedial thickening and enlargement of ossification. (D) Fused type which means fusion of the bilateral ossified masses at the midline. (E) Tuberous type which means anterior growth of the fused mass of ossification. 

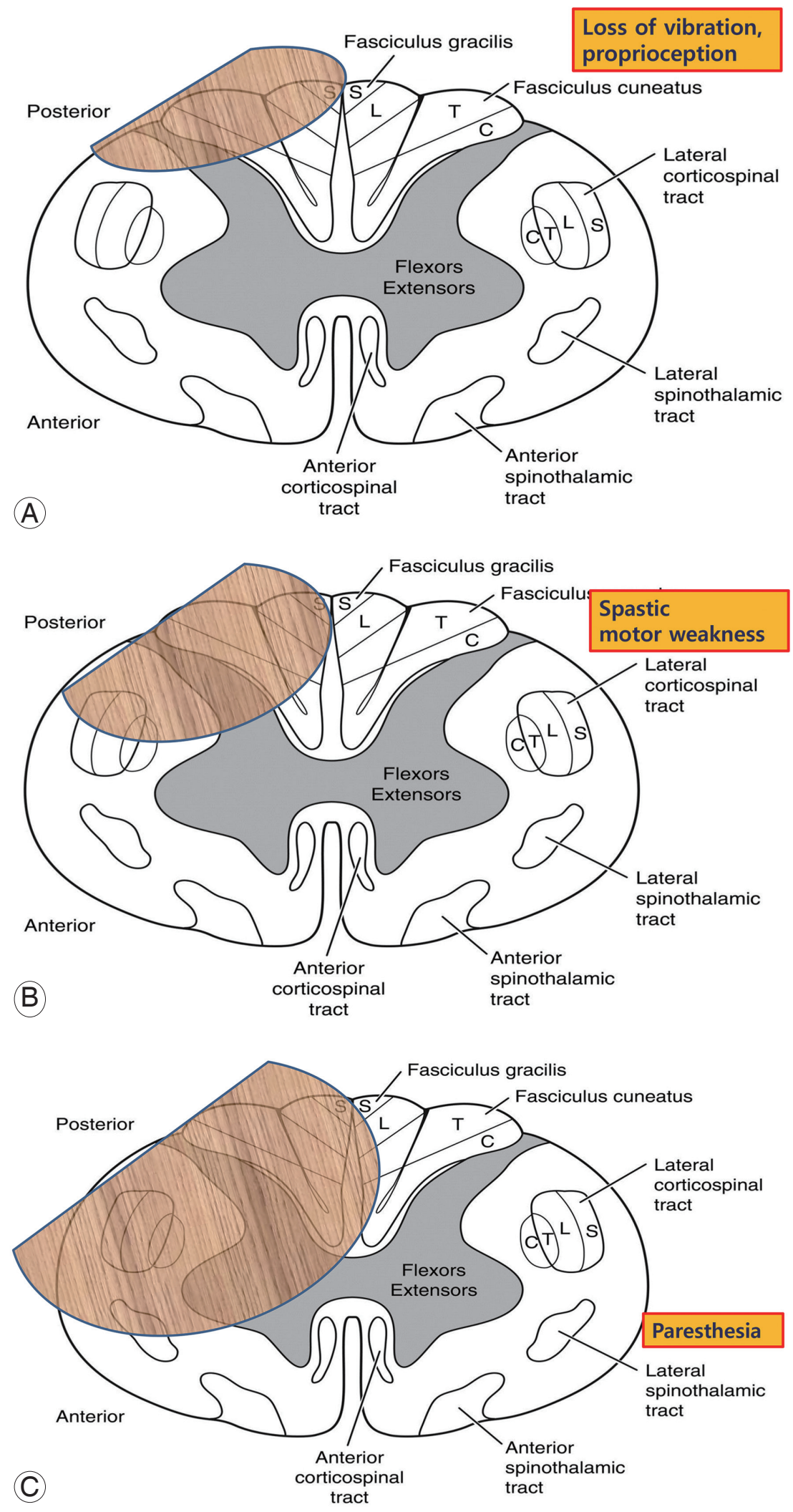

Fig. 2. (A) The ossified ligament compresses the posterior column which transmits the sensation of vibration and proprioception. (B) An enlarged ossified ligament compresses the lateral corticospinal tract which carries descending motor signals. (C) A more enlarged ossified mass compresses the lateral spinothalamic tract which carries ascending sensory signals. S, sacral; $L$, lumbar; T, thoracic; $\mathrm{C}$, cervical. 
of pain and temperature sensation are rare [24]. In imaging investigations, it is not easy to discover this lesion through simple radiography because the lower thoracic spine is overlapped by the liver and the upper thoracic spine is overlapped by the shoulders. An MRI examination is cardinal in the case of myelopathy. T2 sagittal MRI is most instrumental for examining the whole spine and discovering multiple OLFs. Furthermore, it is helpful for determining prognosis through the signal changes of the spinal cord $[9,25,26]$. However, the differential diagnosis of hypertrophy or calcification is difficult even with an MRI. Thus, a CT examination is important for making

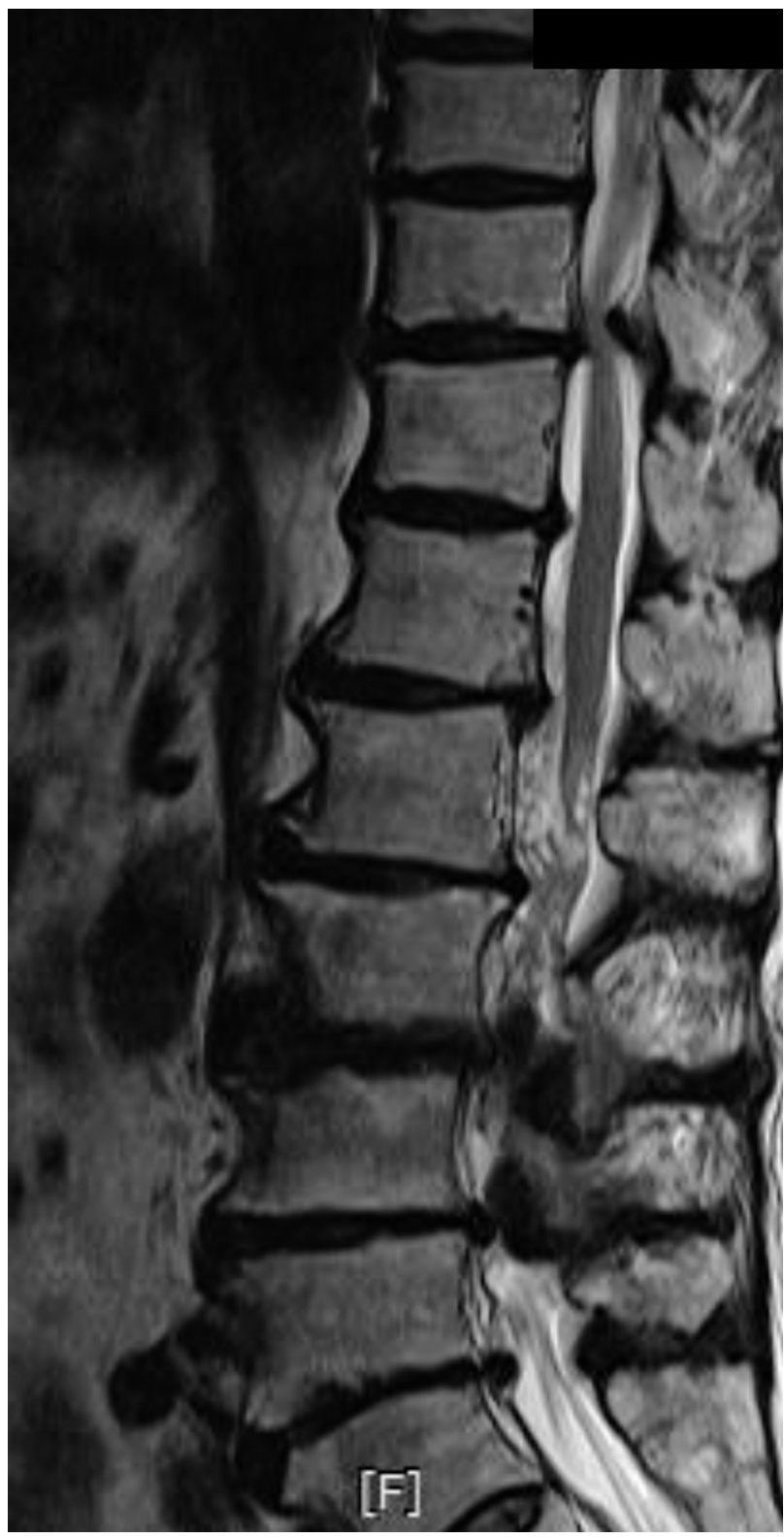

Fig. 3. T10-11 ossification of the ligamentum flavum is associated with distal lumbar spinal stenosis.
Table 1. Options of surgical decompression

\begin{tabular}{l}
\hline Laminotomy \\
Laminoplasty \\
En block laminectomy+dural excision leaving arachnoid \\
En block laminectomy+dural excision+patch graft \\
Laminectomy+floating ossified dura mater \\
\hline
\end{tabular}

Table 2. Poor prognostic factors

\begin{tabular}{l}
\hline Severe preoperative symptoms \\
Long duration of symptoms before surgery \\
Rapid onset of symptoms \\
Dural adhesion and ossification \\
Intramedullary high signal intensity \\
Severity of morphological classification \\
Multi-level \\
Old age \\
\hline
\end{tabular}

an exact diagnosis and for setting up a surgical plan [27]. In the case of accompanying lumbar spinal diseases, the clinical symptoms may become vague and confusing, making it easy for clinicians to miss the exact diagnosis (Fig. 3). That is the reason why whole spine sagittal T2 MRI is important to perform. A double crush can make the symptoms more severe and the surgical outcome worse [28].

\section{Atypical Progression}

An OLF usually shows slow progression of the myelopathy. However, in the case of acute compression fractures at the index segments, an acute spinal cord injury can develop. Acute myelopathy cases show a poorer prognosis (Fig. 4) [19]. Iatrogenic spinal fusion or ankylosis of the distal segments can cause the myelopathy to progress more rapidly than usual (Fig. 5).

\section{Treatment and Prognosis}

Conservative treatment does not work. Surgical decompression is necessary and should be done as soon as symptoms develop. The options of decompression surgery are shown in Table 1. The pertinent method according to the classification is French type laminectomy up to the enlarged type. Bilaterally ossified ligaments can be excised separately. En bloc laminectomy is necessary 
above the fused type. Below the extended type without dural adhesions, decompression can be performed with laminotomy or laminoplasty. The universal method, bi- lateral laminectomy and excision of ossified ligament, is the third technique used. The sequence of decompression is as follows: the inferior articular processes and the in-

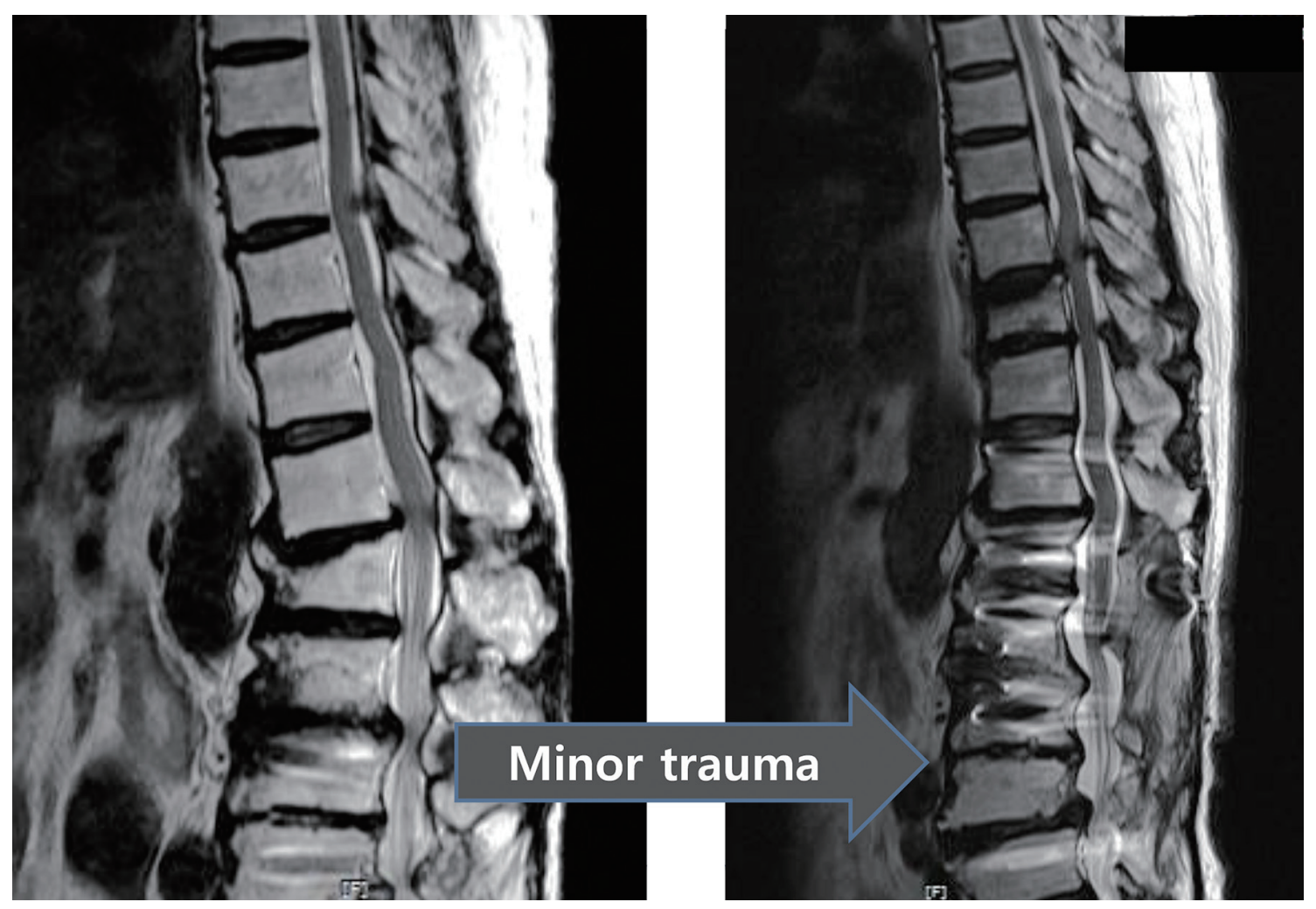

Fig. 4. T10-11 ossification of the ligamentum coexisting with traumatic kyphosis and spinal stenosis of L1-2 and L3-4. After spinal fusion surgery up to L1, spinal cord injury developed secondary to a T11 trivial compression fracture.

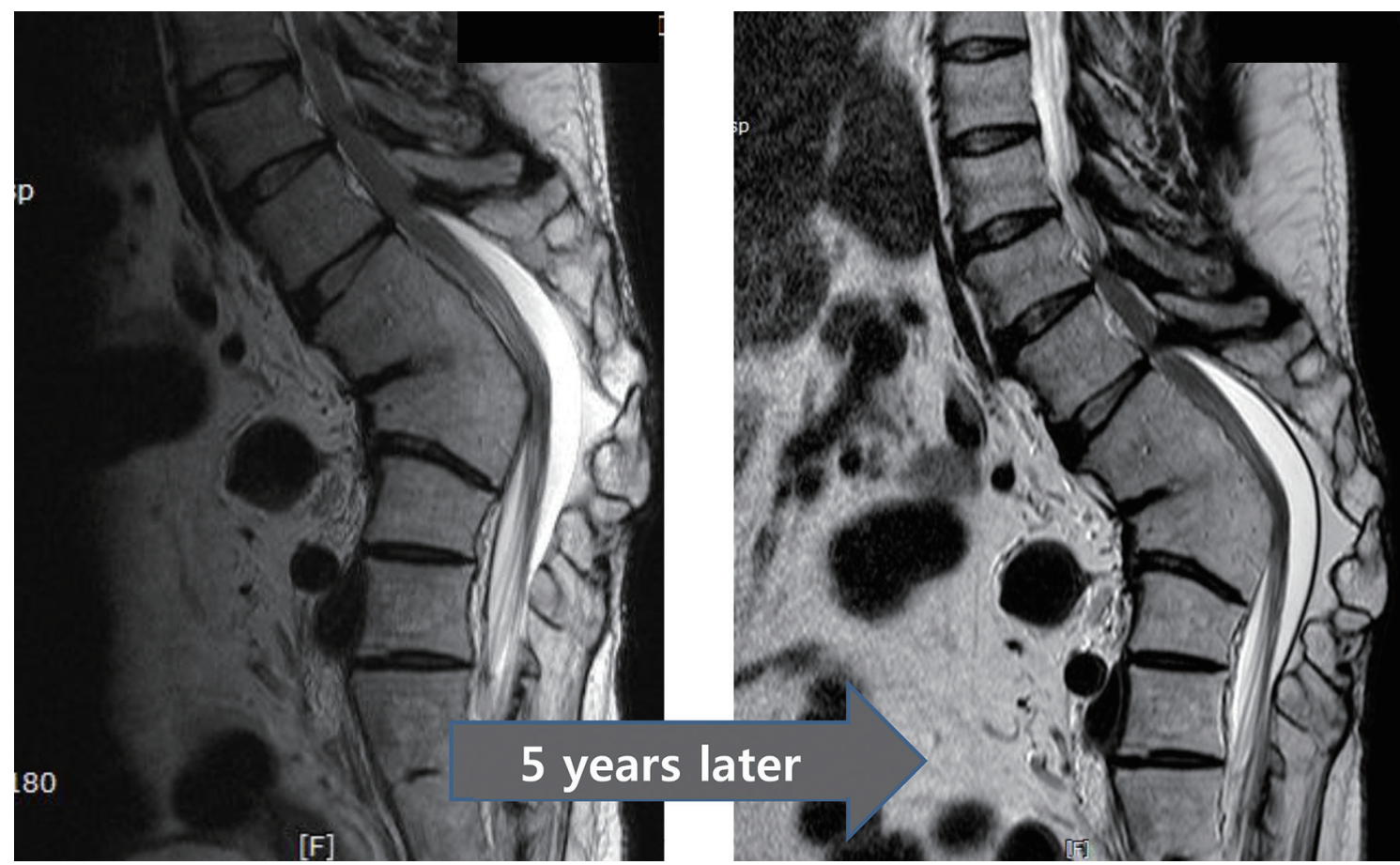

Fig. 5. Small-sized ossification of the ligamentums at the distal thoracic spine show unusually rapid progression due to distal lumbar kyphotic ankylosis. 
ferior lamina of the vertebra above are excised; then the ossified ligament is separated from the dura mater; next, the ossified ligament and superior articular processes of the inferior vertebra are ground into a paper-thin plate; and finally, the thin bony plate is removed [29]. However, in the case of ossification up to the dura mater, the fourth and fifth methods should be used. Total excision of the ossified dura mater and insertion of a patch graft is usually followed by massive cerebrospinal fluid (CSF) leakage and a pseudomeningocele. The method which floats the ossified dura mater, i.e., floating laminectomy, is feasible; however, dural floating will be insufficient in cases where the dural ossification extends to the vertebral foramen. Fortunately, the floated ossified mass usually atrophies and the intradural space widens gradually as time goes by. The pressure of the epidural venous plexus and dural pulsation are considered to contribute to this phenomenon [30]. Dural ossification develops in $11 \%$ to $40 \%$ [15,31-35]. There are two CT findings which predict dural ossification. The first one is an ossified mass which encompasses more than $2 / 3$ of the dura mater, i.e., the comma sign. The second one is a low-signal line between the parallel bone plates, which looks like a railroad track, i.e., the tram track sign (Fig. 6) [33]. In the case of dural ossification, surgical decompression will be demanding and complications will be more frequent; however, the influence on the final outcome is controversial. There has been so far no united agreement on the topic of fusion being added to the decompression. Theoretically, a con- tinuing tensile force on the decompression site may affect the rate of local recurrence and the development of local kyphosis. There have been several studies which support additional fusion [26,27,36-38].

The prognosis of surgical treatment is relatively favorable compared with other causes of thoracic myelopathy. Preservation of the anterior spinal artery, which is a major supplier of the spinal cord, may be the reason. The improvement after decompression is not complete as improvement is usually about $50 \%$. This rate has still not been increased $[13,32,39,40]$. The prognostic factors are shown in Table $2[1,26,27,31,40-44]$. They are somewhat different according to the authors. The most important factors in most studies are the severity of the preoperative symptoms and the time interval before the decompression surgery. Therefore, early diagnosis and early decompression are the most important factors for obtaining better outcomes.

\section{Conclusions}

OLF causes a slow progressive thoracic myelopathy. It develops in East Asians more frequently; however, the incidence is rare. The spinal cord is compressed from the posterior side; hence, patients show a loss of balanced walking, similar to posterior cord syndrome, at first. Spastic motor paralysis develops as the disease progresses, and patients then show severe gait disturbance. Conservative treatment does not work for this disorder.

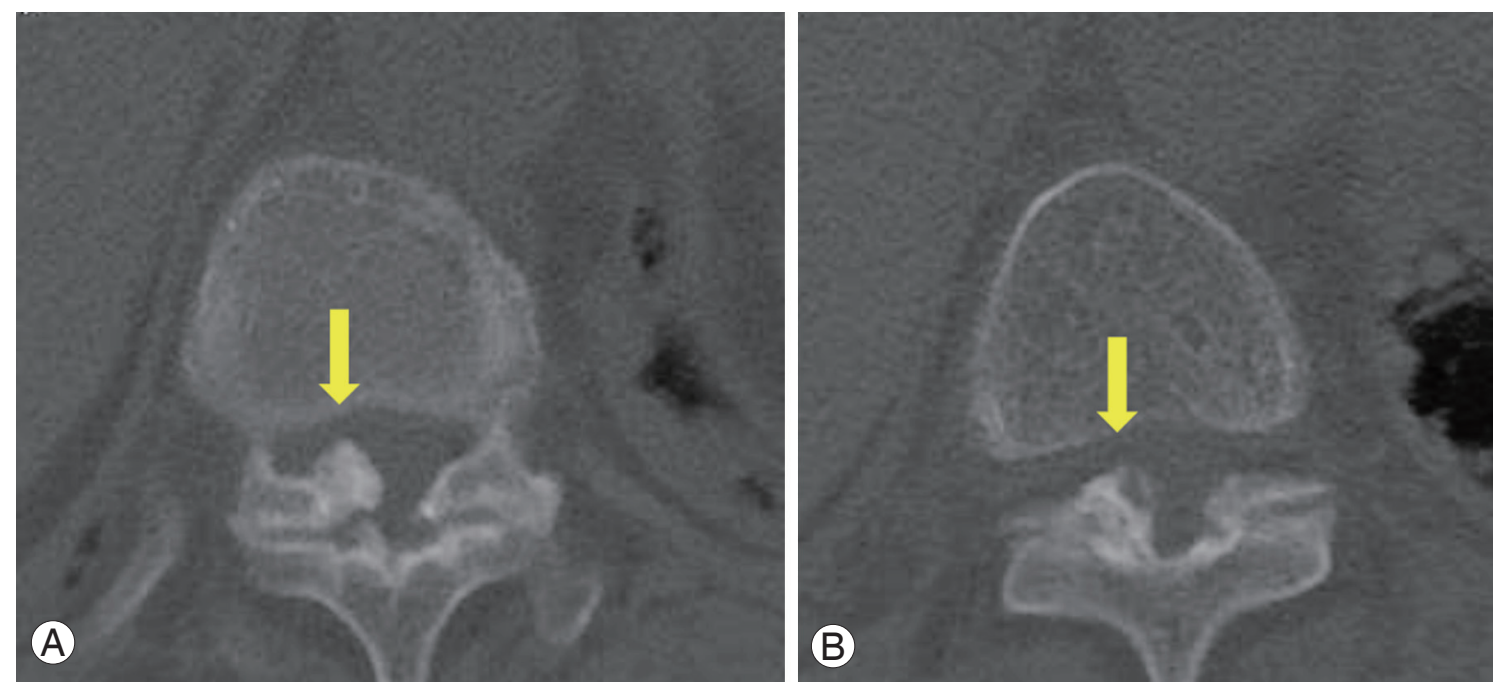

Fig. 6. Computed tomography findings which predict dural ossification. (A) A comma sign, which means a high-signal ossified mass encompasses more than 2/3 of the dura mater (arrow). (B) A tram track sign, which means a low-signal line between parallel high signal plates (arrow). 
Prompt surgical decompression is necessary when myelopathic symptoms develop. The more severe the preoperative symptoms are and the longer the decompression surgery is delayed, the poorer the surgical outcome. Though the prognosis is better than with other causes of thoracic myelopathy, progress in improving treatment is still not complete. An acute severe myelopathy can develop after a minor trauma to a pre-existing OLF, in which case the prognosis is not so favorable.

\section{Conflict of Interest}

No potential conflict of interest relevant to this article was reported.

\section{References}

1. Fong SY, Wong HK. Thoracic myelopathy secondary to ligamentum flavum ossification. Ann Acad Med Singapore 2004;33:340-6.

2. Miyasaka K, Kaneda K, Sato S, et al. Myelopathy due to ossification or calcification of the ligamentum flavum: radiologic and histologic evaluations. AJNR Am J Neuroradiol 1983;4:629-32.

3. Guo JJ, Luk KD, Karppinen J, Yang H, Cheung KM. Prevalence, distribution, and morphology of ossification of the ligamentum flavum: a population study of one thousand seven hundred thirty-six magnetic resonance imaging scans. Spine (Phila Pa 1976) 2010;35:51-6.

4. Hanakita J, Suwa H, Nagayasu S, Nishi S, Ohta F, Sakaida H. Clinical analysis of ossified thoracic ligaments and thoracic disc hernia. Neurol Med Chir (Tokyo) 1991;31:936-42.

5. Arafat QW, Jackowski A, Chavda SV, West RJ. Case report: ossification of the thoracic ligamenta flava in a Caucasian: a rare cause of myelopathy. Br J Radiol 1993;66:1193-6.

6. Coulier B, Ghosez JP, Mailleux P. Computed tomography diagnosis of symptomatic ossification of the thoracic flaval ligaments. JBR-BTR 1998;81:137-40.

7. Tokala DP, Lam KS, Prince HG. Ossification of the proximal thoracic ligamenta flava causing acute myelopathy in a Caucasian: case report and literature review. Spinal Cord 2007;45:310-3.

8. Li H, Jiang LS, Dai LY. Hormones and growth factors in the pathogenesis of spinal ligament ossification.
Eur Spine J 2007;16:1075-84.

9. Hanakita J, Suwa H, Ohta F, Nishi S, Sakaida H, Iihara K. Neuroradiological examination of thoracic radiculomyelopathy due to ossification of the ligamentum flavum. Neuroradiology 1990;32:38-42.

10. Maigne JY, Ayral X, Guerin-Surville H. Frequency and size of ossifications in the caudal attachments of the ligamentum flavum of the thoracic spine. Role of rotatory strains in their development: an anatomic study of 121 spines. Surg Radiol Anat 1992;14:11924.

11. Fukuyama S, Nakamura T, Ikeda T, Takagi K. The effect of mechanical stress on hypertrophy of the lumbar ligamentum flavum. J Spinal Disord 1995;8:12630.

12. Kashiwagi K. Histological changes of the lumbar ligamentum flavum with age. Nihon Seikeigeka Gakkai Zasshi 1993;67:221-9.

13. Okada K, Oka S, Tohge K, Ono K, Yonenobu K, Hosoya T. Thoracic myelopathy caused by ossification of the ligamentum flavum. Clinicopathologic study and surgical treatment. Spine (Phila Pa 1976) 1991;16:280-7.

14. Yayama T, Uchida K, Kobayashi S, et al. Thoracic ossification of the human ligamentum flavum: histopathological and immunohistochemical findings around the ossified lesion. J Neurosurg Spine 2007;7:184-93.

15. Li F, Chen Q, Xu K. Surgical treatment of 40 patients with thoracic ossification of the ligamentum flavum. J Neurosurg Spine 2006;4:191-7.

16. Tsukamoto N, Maeda T, Miura H, et al. Repetitive tensile stress to rat caudal vertebrae inducing cartilage formation in the spinal ligaments: a possible role of mechanical stress in the development of ossification of the spinal ligaments. J Neurosurg Spine 2006;5:234-42.

17. Misawa H, Ohtsuka K, Nakata K, Kinoshita H. Embryological study of the spinal ligaments in human fetuses. J Spinal Disord 1994;7:495-8.

18. Shenoi RM, Duong TT, Brega KE, Gaido LB. Ossification of the ligamentum flavum causing thoracic myelopathy: a case report. Am J Phys Med Rehabil 1997;76:68-72.

19. Park BC, Min WK, Oh CW, et al. Surgical outcome of thoracic myelopathy secondary to ossification of ligamentum flavum. Joint Bone Spine 2007;74:600-5. 
20. Smith DE, Godersky JC. Thoracic spondylosis: an unusual cause of myelopathy. Neurosurgery 1987;20:589-93.

21. Kubota T, Kawano H, Yamashima T, Ikeda K, Hayashi M, Yamamoto S. Ultrastructural study of calcification process in the ligamentum flavum of the cervical spine. Spine (Phila Pa 1976) 1987;12:317-23.

22. Sushil P, Anant K. Ossified-calcified ligamentum flavum causing dorsal cord compression with computed tomography-magnetic resonance imaging features. Surg Neurol 1994;41:441-2.

23. Sato T, Tanaka Y, Aizawa T, Koizumi Y, Kokubun S. Surgical treatment for ossification of ligamentum flavum in the thoracic spine and its complications. Spine Spinal Cord 1998;11:505-10.

24. Giulioni M, Zucchelli M, Damiani S. Thoracic myelopathy caused by calcified ligamentum flavum. Joint Bone Spine 2007;74:504-5.

25. Sugimura H, Kakitsubata Y, Suzuki Y, et al. MRI of ossification of ligamentum flavum. J Comput Assist Tomogr 1992;16:73-6.

26. Trivedi P, Behari S, Paul L, Banerji D, Jain VK, Chhabra DK. Thoracic myelopathy secondary to ossified ligamentum flavum. Acta Neurochir (Wien) 2001;143:775-82.

27. Nishiura I, Isozumi T, Nishihara K, Handa $H$, Koyama T. Surgical approach to ossification of the thoracic yellow ligament. Surg Neurol 1999;51:368-72.

28. Matsumoto Y, Harimaya K, Doi T, et al. Clinical characteristics and surgical outcome of the symptomatic ossification of ligamentum flavum at the thoracic level with combined lumbar spinal stenosis. Arch Orthop Trauma Surg 2012;132:465-70.

29. Kang KC, Lee CS, Shin SK, Park SJ, Chung CH, Chung SS. Ossification of the ligamentum flavum of the thoracic spine in the Korean population. J Neurosurg Spine 2011;14:513-9.

30. Miyashita T, Ataka H, Tanno T. Spontaneous reduction of a floated ossification of the ligamentum flavum after posterior thoracic decompression (floating method); report of a case (abridged translation of a primary publication). Spine J 2013;13:e7-9.

31. Aizawa T, Sato T, Sasaki H, Kusakabe T, Morozumi N, Kokubun S. Thoracic myelopathy caused by ossification of the ligamentum flavum: clinical features and surgical results in the Japanese population. J Neurosurg Spine 2006;5:514-9.

32. Miyakoshi N, Shimada Y, Suzuki T, et al. Factors re- lated to long-term outcome after decompressive surgery for ossification of the ligamentum flavum of the thoracic spine. J Neurosurg 2003;99:251-6.

33. Muthukumar N. Dural ossification in ossification of the ligamentum flavum: a preliminary report. Spine (Phila Pa 1976) 2009;34:2654-61.

34. Sun XZ, Chen ZQ, Qi Q, et al. Diagnosis and treatment of ossification of the ligamentum flavum associated with dural ossification: clinical article. J Neurosurg Spine 2011;15:386-92.

35. Wang W, Kong L, Zhao H, et al. Thoracic ossification of ligamentum flavum caused by skeletal fluorosis. Eur Spine J 2007;16:1119-28.

36. Kurosa Y, Yamaura I, Nakai O, Shinomiya K. Selecting a surgical method for thoracic myelopathy caused by ossification of the posterior longitudinal ligament. Spine (Phila Pa 1976) 1996;21:1458-66.

37. van Oostenbrugge RJ, Herpers MJ, de Kruijk JR. Spinal cord compression caused by unusual location and extension of ossified ligamenta flava in a Caucasian male: a case report and literature review. Spine (Phila Pa 1976) 1999;24:486-8.

38. Yonenobu K, Ebara S, Fujiwara K, et al. Thoracic myelopathy secondary to ossification of the spinal ligament. J Neurosurg 1987;66:511-8.

39. Chen XQ, Yang HL, Wang GL, et al. Surgery for thoracic myelopathy caused by ossification of the ligamentum flavum. J Clin Neurosci 2009;16:1316-20.

40. He S, Hussain N, Li S, Hou T. Clinical and prognostic analysis of ossified ligamentum flavum in a Chinese population. J Neurosurg Spine 2005;3:348-54.

41. Ando K, Imagama S, Wakao N, et al. Examination of the influence of ossification of the anterior longitudinal ligament on symptom progression and surgical outcome of ossification of the thoracic ligamentum flavum: a multicenter study. J Neurosurg Spine 2012;16:147-53.

42. Liao CC, Chen TY, Jung SM, Chen LR. Surgical experience with symptomatic thoracic ossification of the ligamentum flavum. J Neurosurg Spine 2005;2:34-9.

43. Mohindra S, Gupta R, Chhabra R, Gupta SK. Compressive myelopathy due to ossified yellow ligament among South Asians: analysis of surgical outcome. Acta Neurochir (Wien) 2011;153:581-7.

44. Shiokawa K, Hanakita J, Suwa H, Saiki M, Oda M, Kajiwara M. Clinical analysis and prognostic study of ossified ligamentum flavum of the thoracic spine. J Neurosurg 2001;94:221-6. 